\title{
SPACE-PROVISIONS IN THE FLOOR-PLANS OF MODERN ELEMENTARY-SCHOOL BUILDINGS
}

\author{
LEONARD V. KOOS \\ University of Minnesota
}

NATURE, MATERIALS, AND METHOD OF THE STUDY

Because of the perennial character of the problems in the domain of school architecture and especially because of the current focalization of attention upon these problems by the commendable efforts at standardization by the Department of School Administration of the National Education Association, some interest should attach to the findings of an investigation of the kinds of space-provision in the floor-plans of recently constructed elementary-school buildings. Such findings should throw light, among other things, on the kinds of space-provisions that are regarded as essential by those authorizing the construction of the buildings and on the recent tendencies in this phase of school architecture.

The elementary-school floor-plans used for the tabulations here presented were reproduced in the issues of the American School Board Journal during the decade 1908-17 (volumes XXXVI-LV), excluding only those plans which for any reason could not be used for such a study, e.g., because the lettering in them was indistinct owing to reduction in size of the original in reproduction; because a full set of floor-plans was not reproduced, one or more of the floors being omitted; or because, as obtains for many small communities, the plans were for a single building designed to accommodate both elementary- and high-school work. The total number of plans used in the tabulation was 126.

In preparation for the work of tabulation the writer first made a working list of kinds of space-provision by examining a score of floor-plans and noting the sorts of space-provision that had been made in them. The names of the 80 classifications found in this way were introduced into a mimeographed form which provided space for tabulation building by building, i.e., there was a column of blank spaces in which were to be recorded the number of times each space-provision had been made in each set of floor-plans. 
Additional blank spaces were provided for other sorts of spaceprovision found which might not obviously classify under the kinds already listed. The task of recording the space-provisions in the mimeographed forms was done as an exercise by the members of a class in city school administration in the University of Washington. Notwithstanding the simple character of the task, the members of the class were given careful oral and written directions regarding the mode of procedure to be followed in tabulation. To each member of the class was assigned one or two volumes of the journal named. After the preliminary work of tabulation had been completed, the writer tested the accuracy of each student's report by checking over the space-provisions recorded for two full sets of floor-plans. When inaccuracies in the work of tabulation done by a student were discovered, all the floor-plans in the volume assigned to this student were rechecked by the writer. The use of this method of tabulating and of checking gives fair assurance of the accuracy of the findings. The entries on the mimeographed forms showed the presence only, not the area, of a space-provision in a floor-plan. This was owing to the fact that too few of the reproductions include dimensions.

The next step in assembling the materials of the study was the final one of making the number and percentage distributions of space-provisions as shown in the tables accompanying this report. In this final step provisions such as furnace-rooms, fanrooms, and coal-pits were excluded because it was found that for some buildings these were left undesignated in basement or ground-floor plans or were provided for in separate or attached structures, plans of which were not reproduced. It is believed that the numbers and percentages that would have resulted from a tabulation of such as were reproduced would not have been representative. The presence of vestibules, light-courts, space for stacks, corridors, etc., was also left out of consideration in the final tabulations.

The fact that the plans were for buildings erected in communities ranging in population from a few hundred to the second largest city of the country made it possible to give some attention to the differences in space-provisions by size of community. Tables I and II show a division of the plans into two groups: (1) those in communities of 10,000 population and less and (2) those in communities of over 10,000 population. As it was desired to test as to kinds of 


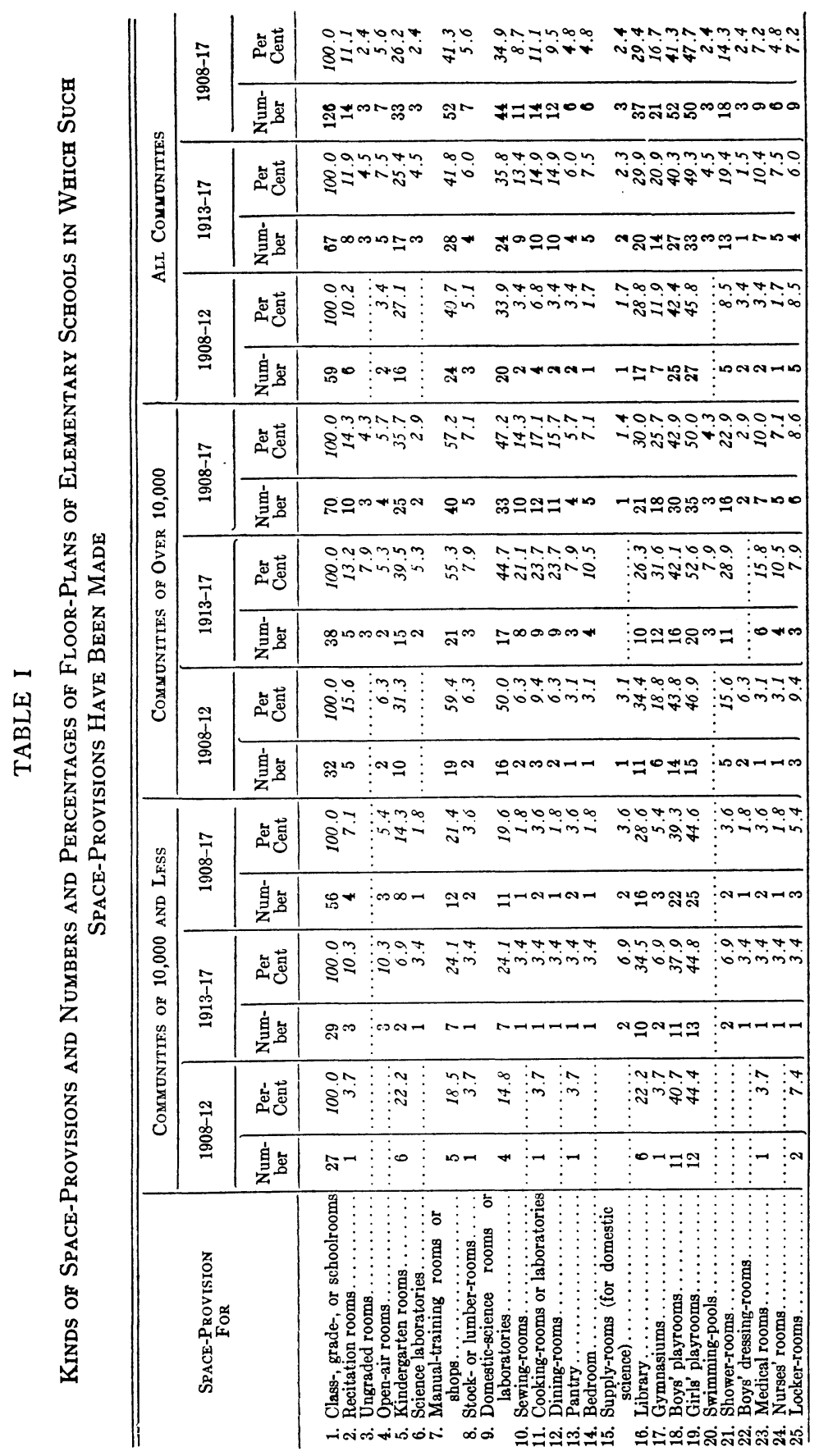

This content downloaded from 080.082.077.083 on January 11, 2018 18:17:22 PM All use subject to University of Chicago Press Terms and Conditions (http://www.journals.uchicago.edu/t-and-c 


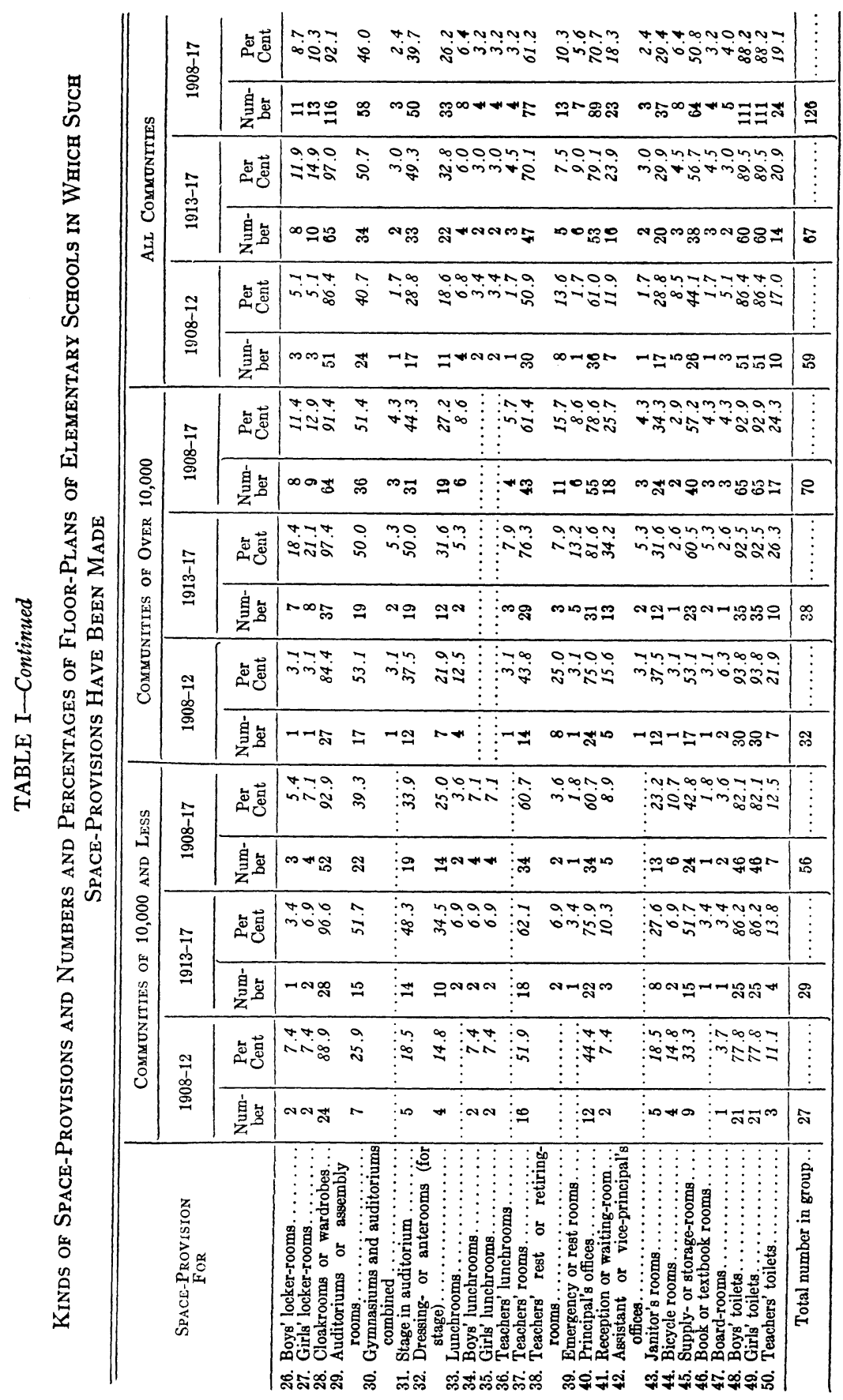

This content downloaded from 080.082.077.083 on January 11, 2018 18:17:22 PM All use subject to University of Chicago Press Terms and Conditions (http://www.journals.uchicago.edu/t-and-c 
space-provision the validity of the statement frequently made, that the decade under consideration was one of rapid change and development in the domain of school architecture, distributions were also made according to the half-decade in which the elementary-school building was erected. The numbers of buildings in each of the four groups resulting may be seen by reference to the lowest row of figures in Table I. In further description of the plans used in the study, it may be said that they have been assembled from 27 states, ranging from Maine to Washington and California, and from Minnesota to Mississippi and Texas; that the median communities represented by the plans reproduced during the half-decades 1908-12 and 1913-17 have approximate populations of 11,000 and 15,000 , respectively; and that both the median communities representing the plans for schools in communities of 10,000 and less for the two half-decades have populations of between 3,000 and 4,000, while the median communities representing the plans for schools in communities of over 10,000 have populations between 50,000 and 60,000 . The approximate equality of each of these pairs of medians argues for the similarity of the pairs of groups they represent and therefore, to some extent, for the validity of the conclusions drawn as to comparative tendencies.

\section{THE KINDS OF SPACE-PROVISION}

The wide range of kinds of space-provision.-The first fact by which one is likely to be struck in glancing down the classifications in the left-hand column of Table $I$ is the wide range of kinds of space-provision. This table, which reports the frequency of appearance of all the space-provisions found at least three times in the 126 floor-plans examined, lists 50 kinds. If to these are added those 47 appearing only once or twice in the floor-plans, of most of which mention is made in succeeding sections of this article, this number is increased to almost 100. And if to this total are added the many kinds of space-provision not reported upon in this study, but including those for boilers, fuel, ashes, fans, engines, flues, vestibules, corridors, light-courts, etc., the final total would mount up easily to 125 different sorts.

Class-, grade-, or schoolrooms.-All schools, of course, are provided with class-, grade-, or schoolrooms, as may be seen by reference to the first row of figures of Table I. The five kinds of rooms immediately following (classifications 2-6) are not nearly as univer- 
sally provided. Of recitation, ungraded, open-air, kindergarten, and science rooms, only the kindergarten rooms are given recognition in any large proportion of cases, recitation rooms finding a place in only a ninth of the plans, open-air rooms in half this proportion, and the remaining two kinds of rooms in but three plans each. By comparing the percentages for the half-decades, we may conclude that most of these special rooms are on the increase, but not at all rapidly, while by comparing the percentages for the smaller and the larger communities we find that the latter much more frequently provide them than the former. The following rooms are assigned in one or two plans each: special study, agriculture, drill, demonstration, departmental, visual instruction, and oral deaf. It is not unlikely that in a few instances rooms for the purposes indicated by the special classifications here named are provided without special designation in the plans examined.

Manual-training and domestic-science rooms.-Classifications 7-15 of Table I and 1-2 of Table II present the facts as to spaceprovisions for manual training and domestic science. In addition to the kinds named, the following are provided in one or two floorplans each: woodworking, bench, machine, mechanical-drawing, sloyd, finishing, tool, bath, living, fitting, and laundry rooms. The former table shows the numbers and percentages of plans in which each of several sorts of space-provision is made, and the latter the total numbers and percentages of floor-plans making some spaceprovision for these two lines of activity. From the latter we see that equal percentages-42.9-of all floor-plans recognize both lines of work, floor-plans in the larger communities providing space for them much more frequently than the smaller, although it is in the latter only that these space-provisions are increasing in frequency. The last fact may be in part explained by the practice in some larger cities of providing manual-training or domestic-science "centers" instead of providing space for these lines of work in all elementary-school buildings. It may be seen in Table $I$ that while the undifferentiated "domestic-science room" is on the increase in the new buildings in smaller communities, it is actually decreasing in frequency in the larger communities. In the latter the proportion of differentiated "cooking-" and "sewing-" rooms seems to be increasing. The special provisions for dining-room, pantry, and bedroom, although not common, are more frequently found in the larger than in the smaller communities. 


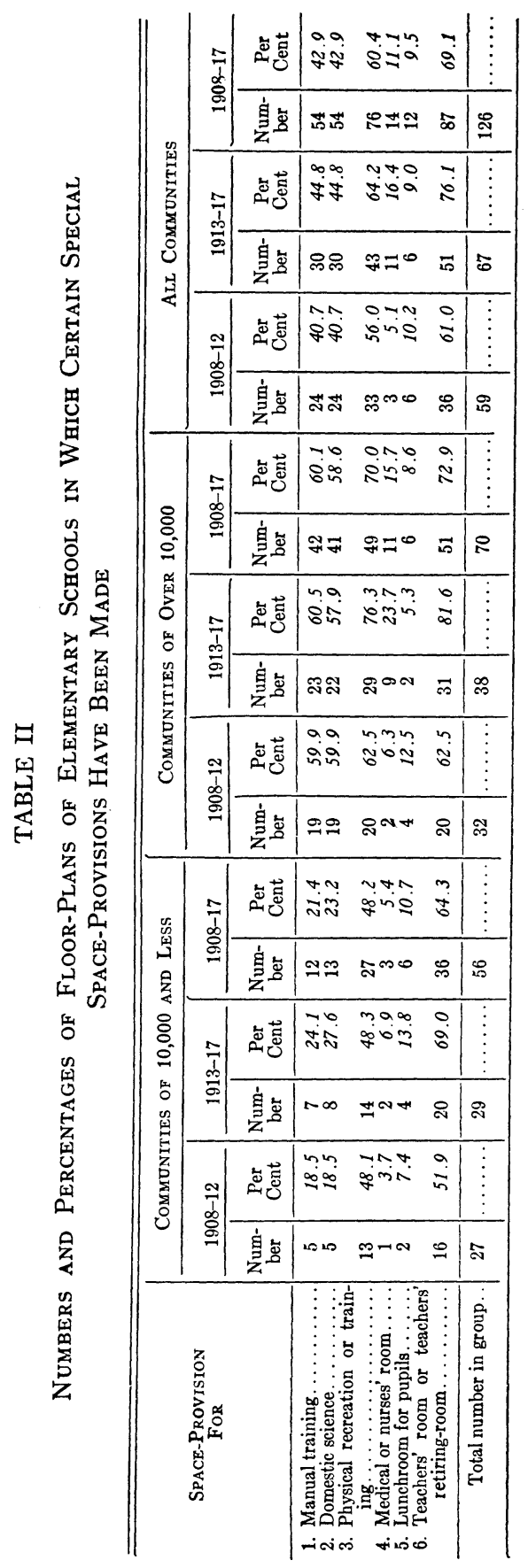

This content downloaded from 080.082.077.083 on January 11, 2018 18:17:22 PM All use subject to University of Chicago Press Terms and Conditions (http://www.journals.uchicago.edu/t-and-c 
Space-provisions for the arts.-These are so infrequently made that they did not find a place in the tables. Each of the following is named once in the 126 floor-plans: "museum and art," "art," "arts and crafts," "clay-modeling," and "music."

Library room.-Only 29.4 per cent of all floor-plans make provision for the library $(I, 16)$. Nor are these rooms notably increasing in frequency. There is little or no difference with regard to this provision between the smaller and the larger communities.

Facilities for physical recreation and training and for health supervision.-The space-provisions for physical recreation and training and for health supervision are shown under classifications 17-24 in Table I and 3-4 in Table II. In addition, a roof playground, a running-track, and a folk-dancing room are reported once each, and girls' dressing-rooms and dental rooms twice in the 126 floor-plans examined. Table II (classification 3) shows that some provision is made for physical recreation or training in approximately three-fif ths of all plans examined, and Table I (classifications $17,18,19,30)$ that this means playrooms much more frequently than gymnasiums. In a few instances both a gymnasium and a girls' playroom are provided. Consonant with this is the fact that, while gymnasiums and girls' playrooms are both increasing in frequency, boys' playrooms are hardly holding their own. Although gymnasiums are more common in the larger than in the smaller communities, playrooms find a place with almost equal frequency in both groups. Shower-rooms are increasing in frequency, especially in the larger communities. Swimming-pools made their first appearance in the second half-decade and then only in the larger communities.

Medical and nurses' rooms, although rather uncommon, are being provided for with increasing frequency, especially in the larger communities (I, 23, 24; II, 4).

Locker-rooms and cloakrooms or wardrobes.-Almost all plans provide for cloakrooms or wardrobes $(I, 28)$ while a relatively small proportion provide rooms for lockers either in common for boys and girls or segregated (classifications 25-27). Most of those plans which include rooms for lockers provide both cloakrooms and locker-rooms, the latter being facilities accompanying gymnasiums and manual-training or domestic-science rooms. It is very seldom that locker-rooms only (and no cloakrooms) are provided in plans for elementary-school buildings. 
Auditoriums or assembly rooms.-These space-provisions find place in almost half the plans examined $(I, 29,30)$, are more common in the larger than in the smaller communities, but are more rapidly increasing in frequency in the latter. "Study-halls" are provided in two additional plans. We should not leave out of account here the fact that gymnasiums are frequently used as auditoriums and that those schools in which the former are provided cannot be said to be unequipped with the latter. The stage in the auditorium or assembly room is usually also included in the plans, while the dressing- or anterooms are provided in approximately two-thirds of the plans that provide for the stage.

Lunchrooms. - A total of but 12 of all the 126 plans make provision for lunchrooms for pupils (I, 33-35 and II, 5). Moreover, they seem not to be increasing in frequency, either in the smaller or in the larger communities. The common lunchroom is found more frequently than is the segregated type. Teachers' lunchrooms $(\mathrm{I}, 36)$ are occasionally provided in the elementary-school plans of the larger cities. A single plan includes a kitchen for the teachers' lunchroom.

Teachers' rooms and emergency or rest rooms.-Teachers' rooms $(\mathrm{I}, 37,38 ; \mathrm{II}, 6)$ are not only provided in a very large proportion of the plans examined, but they are also increasing in frequency in both the smaller and the larger communities. In a very few instances both "teachers' rooms" and "teachers' rest rooms" are assigned. Boys' rest rooms and girls' rooms are found in one or two plans. The "emergency room" or "emergency and rest room" is more often provided during the second than during the first halfdecade, but almost solely in the larger communities.

Office-rooms.-Rooms for the principal's office $(I, 40)$ are found in 70.7 per cent of all plans examined. They are somewhat more common in the larger than in the smaller communities. They are also increasing in frequency, as may be seen by a comparison of the percentages for the two half-decades, but more rapidly in the smaller than in the larger communities. Reception or waitingrooms in connection with principals' offices (I, 41) are not a common space-provision in plans of elementary-school buildings, but they are being provided with increasing frequency, especially in the larger communities. Office-rooms for the assistant principal $(\mathrm{I}, 42)$ are infrequently provided.

Janitors' and storage-rooms.-Janitors' rooms (I, 43) are provided in 29.4 per cent of the 126 plans. There is little tendency to 
provide them with greater frequency, and there is only slight difference in the percentages of the smaller and the larger communities which provide them. Bicycle rooms (I, 44) appear in a small proportion of plans. Supply- and storage-rooms (I, 45) are provided in fully half the plans, are not as common in the smaller as in the larger communities, but appear with increasing frequency in both. Book or textbook rooms $(I, 46)$ are far from a common space-provision. A "utility room" was found once in the plans examined.

Board-rooms.-Board-rooms (I, 47) were reported for 5 of the plans examined. Superintendents', supervisors' and secretaries' offices were each found in one or two plans.

Toilet-rooms.-Boys' and girls' toilets $(I, 48,49)$ are found in 88.2 per cent of the 126 plans examined. A few of the remaining are no doubt providing satisfactory facilities in adjoining or separate structures, but it is clear that some-and these not a negligible proportion-must be neglecting to provide anything better than the insanitary and immoral outdoor privy. Almost a fifth of the plans -approximately twice as many in the larger as in the smaller communities-make provision also for teachers' toilets (I, 50).

Relative frequency of the kinds of space-provision.-Before leaving consideration of the particular space-provisions, it will be worth while to turn our attention to their relative frequency, which is not readily apparent in Table $I$. In order to emphasize relative frequency, the space-provisions have been grouped according as they fall in decreasing percentage classifications and ranked in the order of decreasing frequency in all the 126 elementary-school floor-plans. The results of such arrangement and ranking are shown in Table III. As there are many kinds of space-provision appearing with identical percentages of frequency, the total num-

TABLE III

Space-Provisions in the Floor-Plans of Elementary-School Buildings in the Order of Frequency of Appearance

90-100 per cent:

1. Class-, grade-, or schoolrooms, 100.0

2. Cloakrooms or wardrobes, 92.1 80-90 per cent:

3. Boys' toilets, 88.2

3. Girls' toilets, 88.2

70-80 per cent:

4. Principal's office, 70.7 
60-70 per cent:

5. Teachers' room, 61.2

50-60 per cent:

6. Supply- or storage- room, 50.8

40-50 per cent:

7. Girls' playroom, 47.7

8. Auditorium or assembly room, 46.0

9. Boys' playroom, 41.3

9. Manual-training room, 41.3

30-40 per cent:

10. Stage in auditorium, 39.7

11. Domestic-science room, 34.9

20-30 per cent:

12. Library, 29.4

12. Janitor's room, 29.4

13. Kindergarten room, 26.2

13. Dressing- or anterooms to stage, 26.2

10-20 per cent:

14. Teachers' toilet, 19.1

15. Reception or waiting-room (to principal's office), 18.3

16. Gymnasium, 16.7

17. Shower-rooms, 14.3

18. Recitation rooms, 11.1

18. Cooking-room, 11.1

19. Girls' locker-room, 10.3

19. Teachers' rest or retiring-room, 10.3

5-10 per cent:

20. Dining-room, 9.5

21. Boys' locker-room, 8.7

21. Sewing-room, 8.7

22. Medical room, 7.2

22. Locker-room, 7.2

23. Lunchroom, 6.4

23. Bicycle room, 6.4

24. Open-air room, 5.6

24. Stock- or lumber-room (for manual training), 5.6

24. Emergency or rest room, $\mathbf{5 . 6}$

2.4-5 per cent:

25. Pantry (for domestic science), 4.8

25. Bedroom (for domestic science), 4.8

25. Nurses' room, 4.8

26. Board-room, 4.0

27. Boys' lunchroom, 3.2

27. Girls' lunchroom, 3.2

27. Teachers' lunchroom, 3.2

27. Book or textbook room, 3.2

28. Ungraded room, 2.4 
28. Science laboratory, 2.4

28. Supply-room (for domestic science), 2.4

28. Swimming-pool, 2.4

28. Boys' dressing-room, 2.4

28. Gymnasium and auditorium (combined), 2.4

28. Assistant or vice-principal's office, 2.4

ber of ranks is only slightly more than half the number of kinds listed in Table I. Examination of the upper portion of Table III indicates that 7 of all the 50 sorts of space-provisions are made in more than 50 per cent of the floor-plans. In other words, in practice a majority at least of the groups of officials which have authorized the construction of the 126 elementary-school buildings whose plans were examined for this study regard the following as "minimum essentials" of such buildings: class- or graderooms, cloakrooms or wardrobes, a principal's office, a teachers' room, a supplyor storage-room, and boys' and girls' toilets. By referring to Table II we may see that to this list should be added some space-provision for physical recreation or training. . Further reference to Tables I and II will show that, if only plans in cities over 10,000 population are considered, to this list of minimum essentials may be added space-provisions for manual training, domestic science, and an auditorium or assembly room, and that if only plans in the smaller communities are given consideration, from it must be subtracted the supply- or storage-room. The reader will find it interesting to note the very wide range of space-provisions not included in these minimum essentials. Indeed, he can hardly fail to be surprised at the low rankings and low percentages of recognition of some of the kinds of space-provision in the lower portions of Table III.

\section{SIGNIFICANCE AND UTILITY OF THE FINDINGS}

The tabulations made for the present study of the floor-plans of recently constructed elementary-school buildings show a wide variety of space-provisions: 50 different kinds of space-provision were found to appear three or more times in the 126 plans examined. If to these are added those which appeared but once or twice and others which for any reason were excluded from the tabulations, the total number will be found to exceed 100 .

The first implication of such an array of kinds of space-provision likely to be drawn, viz., that all or most of the recently constructed elementary-school buildings are well adapted to meet the demands 
of the best modern theory and practice, is subject to serious qualification. It appears that only 7 of all the sorts of space-provisions are made in a majority of these floor-plans. They are: class-, grade-, or schoolrooms, cloakrooms or wardrobes, a principal's office, a teachers' room, a supply- or storage-room, and boys' and girls' toilets. Although the larger communities tend to make additions to this list of what school authorities seem to regard as the minimum essentials of an elementary-school building, the spaceprovisions added in a majority of these communities are few. They are space-provisions for manual training, domestic science, and an auditorium or assembly room. It must be remembered that even in these communities large proportions of the plans do not include the additional provisions just named. The situation is, of course, more unsatisfactory in the smaller community.

Notwithstanding the fact that the figures for the second halfdecade indicate that increasing proportions of the communities, both large and small, are extending their conceptions of what should be included in the floor-plans of an elementary-school building, it is discouraging to find the structures in which the educational process must be carried on lagging as far as they do behind the demands of the best modern theory and practice. This discouragement is made more poignant when it is brought to mind that the plans examined do not constitute a random sample of the plans of elementary-school buildings constructed in the country during the decade. They must be superior to such a random sample since they include those plans and buildings in which school officers or architects take sufficient pride to prompt them to submit those plans for reproduction and publication in an important educational periodical. There would in general be less desire to submit for such reproduction and publication the floor-plans of buildings more conservative as to kinds of space-provision than those used as the basis of this study. Thus, it may be stated with some assurance that the typical elementary-school building erected during the half-decade only recently closed still fails to give recognition to the need of providing shops, kitchens, and other rooms for training in the practical arts, to provide the facilities for physical training and recreation, to open up the opportunities of education and recreation of pupils and others in the community which are made possible through provision of an auditorium, not to mention a number of 
other important aspects of modern education suggested by such a list of space-provisions as has been found in this study.

There has been some tendency in investigations in the educational world to accept the typical as the standard. While there is of ten merit in this procedure, we have in the findings of this study an illustration of the danger of following it blindly: to accept the typical elementary-school building of recent construction as the standard would be to hinder educational progress. Such a study, however, may have its value for school officers contemplating the erection of elementary-school buildings in that it provides a fairly complete catalogue of the many sorts of space-provisions now being made in elementary-school buildings. Because elementary education is the universal education and, therefore, should not deviate markedly below a high standard from community to community, careful examination of such a list should prove of considerable assistance. This type of use is enhanced by the fact that the study also discovers the tendencies, i.e., shows which space-provisions are increasing in frequency of appearance in the plans. 